Mr Nebojša Gaćeša, potpukovnik, dipl. inž

Vojnoizdavački zavod,

Beograd

\section{SIMULACIONI MODEL SISTEMA ZA UPRAVLJANJE LETOM PROTIVBRODSKE RAKETE}

UDC: 623.462 .3

Rezime:

U radu je analiziran program za simulaciju sistema za upravljanje letom protivbrodske rakete sa radarskom glavom za samonavođenje. Analiziran je matematički model rakete, model autopilota i model cilja. Ovakvim pristupom dobijen je rezultat koji omogućava uspostavljanje realnijeg procesa praćenja leta konkretne protivbrodske rakete, budući da upravljanje letom rakete na celoj trajektoriji ima znatne prednosti u odnosu na nevođene projektile, pre svega zbog mogućnosti gađanja pokretnih ciljeva. Simulacioni model upravljanja letom rakete pruža mogućnosti za dalje proučavanje ove klase raketa.

Ključne reči: protivbrodska raketa, sistem za upravljanje letom, vođenje, radarska glava za samonavođenje, autopilot, simulacija, simulacioni model.

\title{
MODEL FOR SIMULATING THE FLIGHT CONTROL SYSTEM OF A ANTISHIP MISSILE
}

Summary:

The paper analyzes a program for simulating the flight control of an antiship missile with the radar seeker. The paper analyzes a matematic missile model, an autopilot model and a target model. Thus obtained results enable a more realistic process of flight tracking of a particular antiship missile as the missile guidance along the whole trajectory provides many advantages over unguided projectiles, primarily because of the possibility to fire at moving targets. The flight control simulation model enables further study of this missile class.

Key words: antiship missile, flight control system, guidance, radar seeker, autopilot, simulation, simulation model.

\section{Uvod}

Pod sistemom za upravljanje letom rakete (SULR) podrazumevaju se svi uređaji koji obezbeđuju susret vođene rakete sa ciljem. Zadatak sistema za upravljanje letom rakete je da eliminiše ili dovede $u$ dopuštene granice greške gađanja po daljini i pravcu, u sledećim fazama:

- određivanje grešaka, tj. veličine odstupanja rakete od zadate (potrebne) trajektorije leta rakete;
- stvaranje signala upravljanja, čija veličina zavisi od veličine greške odstupanja, a znak (,,+“ ili ,--“) od smera odstupanja;

- dovođenje signala upravljanja na organe upravljanja raketom (na kormilarske mašine i dalje na elerone, kormila pravca i kormila visine);

- određivanje željenog uglovnog položaja rakete u prostoru, tj. obezbeđivanje uglovne stabilizacije rakete u odnosu na njen centar težišta. 
Sistem za upravljanje letom rakete radi na sledeći način.

Podaci o položaju cilja i položaju rakete, koji su određeni na neki način $(\mathrm{u}$ zavisnosti od načina vođenja rakete) kao koordinate cilja i koordinate rakete, dolaze na ulaz računarskog bloka i u njemu se obrađuju na takav način da se proračuna trajektorija leta rakete, koja će obezbediti susret vođene rakete sa ciljem. Ako se uređaj za vođenje rakete nalazi izvan rakete (u slučaju teleupravljanja), proračunati signali upravljanja predaju se radio-putem, posredstvom predajnika komandnih signala (komandni signali nose informaciju o odstupanju rakete od cilja). Proračun trajektorije leta rakete neprekidno se koriguje, u zavisnosti od manevra cilja. Grešku sistema za upravljanje letom rakete predstavlja odstupanje rakete od željene, tj. računarom proračunate trajektorije leta rakete. U zavisnosti od veličine i smera greške, stvaraju se signali upravljanja koji se vode na ulaz komparatora automata za stabilizaciju rakete. Pod dejstvom signala sa izlaza komparatora, koji se pojačavaju u pojačivaču autopilota, aktiviraju se kormilarske mašine, odnosno izvršni motori, čime se kormila zakreću u stranu koja raketu dovodi na proračunatu trajektoriju leta rakete, odnosno sve dotle dok signal na izlazu komparatora ne bude jednak nuli. Kada nema odstupanja od proračunate trajektorije leta, signali upravljanja na izlazu komparatora jednaki su nuli i automat za stabilizaciju rakete stabilizuje raketu na potrebnoj trajektoriji. Ako na raketu, iz bilo kojih razloga, deluje neki neželjeni spoljašnji poremećaj, tada će veličinu i smer delovanja takvog poreme- ćaja registrovati osetljivi elementi - senzori (npr: tri slobodna žiroskopa - kursa, visine $\mathrm{i}$ bočnog nagiba, te radio-visinomer), koji će na svom izlazu dati odgovarajući signal koji se vodi na jedan od ulaza komparatora. Sa izlaza komparatora, razlika signala ili signal greške pojačavaju se na pojačivaču, te vode na izvršni motor koji zakreće kormila, a ona aerodinamičkim putem zakreću raketu sve dok se ne otklone posledice neželjenog poremećaja.

\section{Model rakete}

Kretanje rakete, odnosno dinamički model kretanja rakete, pod uticajem spoljnih sila, može se potpuno opisati sa šest diferencijalnih jednačina. Tim modelom omogućava se izračunavanje svih odziva rakete (parametara aksijalnih i ugaonih kretanja). Za raketu koja se kreće kroz atmosferu, spoljne sile su kombinacija sile zemljine teže, sile potiska i aerodinamičkih sila. Poznavanje dinamičkih osobina rakete, kao objekta upravljanja, neophodno je u cilju projektovanja SULR. Model dinamike leta rakete omogućava ocenu njenih globalnih performansi, koje proističu iz njene konstrukcije, kao što su aerodinamička konfiguracija i pogon. Raketa kao objekt upravljanja predstavlja nelinearan, nestacionaran, multivarijabilan sistem. Kako je to sistem koji se predstavlja kompleksnim sistemom jednačina, relativno visokih dimenzija, sa velikim brojem podataka i potrebom za velikom memorijom za njihovo rešenje, vrše se neophodna pojednostavljenja. Stoga se polazi od pretpostavke da je raketa kruto telo, da se 
njeno kretanje podvrgava zakonima o održanju količine kretanja i momenta količine kretanja, te vrši pogodan izbor koordinatnog sistema. Usvaja se da se koordinatni početak poklapa sa centrom inercije i da se koordinatne ose poklapaju sa glavnim osama inercije, te osnosimetričnost rakete, što znači jednakost momenta inercije oko poprečnih osa. Na osnovu navedenih pretpostavki izvodi se odgovarajući sistem nehomogenih, nelinearnih diferencijalnih jednačina [6]. Vektorske diferencijalne jednačine kojima se izražavaju zakoni o održanju količine kretanja i momenta količine kretanja su:

$$
\begin{aligned}
& \frac{d \vec{P}}{d t}=\vec{F} \\
& \frac{d \vec{K}}{d t}=\vec{M}
\end{aligned}
$$

gde $\overrightarrow{\mathrm{P}}$ i $\overrightarrow{\mathrm{K}}$ predstavljaju linearni, odnosno ugaoni moment krutog tela u kretanju $\mathrm{u}$ odnosu na inercijalni koordinatni sistem, a $\vec{F}$ i $\vec{M}$ vektore spoljnih sila, odnosno momenata koji deluju na kruto telo.

\section{Koordinatni sistemi rakete kao objekta upravljanja}

Da bi se opisalo kretanje rakete, neophodno je definisati koordinatne sisteme (KS) u odnosu na koje se kretanje posmatra. U simulaciji su korišćeni $\mathrm{KS}$ vezani za zemlju, za telo rakete i za brzinu rakete. Smisao uvođenja pokretnih KS (vezanih za telo rakete i vektor brzine rakete) ogleda se u jednostavnijem projektovanju vektorskih diferencijalnih jednačina (1) i (2) na ose datih KS.

a) Koordinatni sistem vezan za zemlju (inercijalni KS)

KS vezan za zemlju ili zemaljski KS $\left(\mathrm{OX}_{0} \mathrm{Y}_{0} \mathrm{Z}_{0}\right)$ vezan je za površinu Zemlje, sa osom $\mathrm{OX}_{0}$ koja leži u ravni paralelnoj sa ravni mesnog horizonta i upravljena je proizvoljno. Osa $\mathrm{OY}_{0}$ usmerena je duž mesne vertikale, a osa $\mathrm{OZ}_{0}$ postavlja se tako da formira desni KS. U zemaljskom KS posmatra se kretanje težišta rakete. Zbog kratkoće leta, brzina znatno manjih od prve kosmičke brzine i leta u predelima atmosfere, pri analizi kretanja rakete taktičke namene moguće je zanemariti



Sl. 1 - Koordinatni sistem vezan za telo rakete (vezani $K S$ ) 
rotaciju Zemlje oko sopstvene ose i zakrivljenost njene površine. Zato se zemaljski KS smatra inercijalnim (nepokretnim u prostoru).

b) Koordinatni sistem vezan za telo rakete (vezani KS)

Koordinatni početak vezanog KS (sl. 1) nalazi se u centru gravitacije tela rakete, osa OX poklapa se sa podužnom osom tela rakete (u pravcu ose simetrije), pozitivno orijentisana u smeru leta rakete i sa osom OY leži u vertikalnoj ravni simetrije. Ose su upravljene duž glavnih osa inercije, jer se u najvećem broju slučajeva glavne ose inercije vrlo blisko poklapaju sa geometrijskim osama simetrije. Osa $\mathrm{OZ}$ je normalna na vertikalnu ravan simetrije u smeru desnog krila rakete.

Položaj osa vezanog KS u odnosu na inercijalni KS određen je skupom Ojlerovih uglova: propinjanja $\vartheta$, skretanja $\Psi$ i valjanja $\gamma$, kao na slici 2 .

Prelaz iz vezanog u inercijalni KS vrši se sledećim redosledom rotacija:

- rotacija oko $\mathrm{OY}_{0}$ ose, u pozitivnom smeru, za ugao skretanja,

- rotacija oko $\mathrm{OZ}_{0}$ ose, u pozitivnom smeru, za ugao propinjanja.

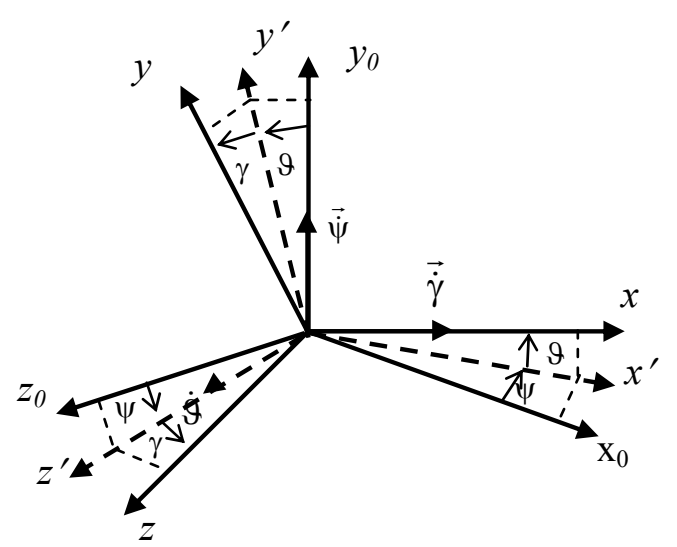

Sl. 2 - Veza između inercijalnog $i$ vezanog $K S$ c) Koordinatni sistem vezan za vektor brzine rakete (brzinski KS)

Prelaz iz vezanog u brzinski KS vrši se:

- rotacijom oko ose OY vezanog KS za napadni ugao $\alpha \mathrm{i}$

- rotacijom oko zakrenute ose $Z_{B}$, koja predstavlja bočnu silu (silu klizanja) - jednačina (6), za ugao klizanja $\beta$.

Kao varijanta brzinskog KS značajan je i tzv. polubrzinski KS, čija osa $\mathrm{OY}_{\mathrm{p}}$ leži u vertikalnoj ravni inercijalnog $\mathrm{KS}\left(\mathrm{OX}_{0} \mathrm{Y}_{0}\right)$, a osa $\mathrm{OZ}_{\mathrm{p}} \mathrm{u}$ horizontalnoj ravni inercijalnog $\mathrm{KS}\left(\mathrm{OX}_{0} \mathrm{Z}_{0}\right)$.

\section{Dinamičke jednačine kretanja rakete}

Detaljno izvođenje jednačina kretanja rakete objašnjeno je u [6] i [7].

Skup 12 skalarnih diferencijalnih jednačina koje opisuju kretanje rakete moguće je predstaviti na sledeći način:

$\left|\begin{array}{l}d V / d t \\ d \Theta / d t \\ d \Psi / d t \\ d \omega_{x} / d t \\ d \omega_{y} / d t \\ d \omega_{z} / d t \\ d \psi / d t \\ d \vartheta / d t \\ d \gamma / d t \\ d x_{0} / d t \\ d y_{0} / d t \\ d z_{0} / d t\end{array}\right|=\left|\begin{array}{l}F_{x p} / m \\ F_{y p} / m V \\ -F_{z p} / m V \cos \Theta \\ M_{x} / I_{x} \\ {\left[M_{y}+\left(I_{z}-I_{x}\right) \omega_{x} \omega_{z}\right] / I_{y}} \\ {\left[M_{z}+\left(I_{x}-I_{y}\right) \omega_{x} \omega_{y}\right] / I_{z}} \\ \left(\omega_{y} \cos \gamma-\omega_{z} \sin \gamma\right) / \cos \vartheta \\ \omega_{y} \sin \gamma+\omega_{z} \cos \gamma \\ \omega_{x}-\left(\omega_{y} \cos \gamma-\omega_{z} \sin \gamma\right) \operatorname{tg} \vartheta \\ V \cos \Theta \cos \Psi \\ V \sin \Theta \\ -V \cos \Theta \sin \Psi\end{array}\right|$ 
U jednačinama (3) na levim stranama su promenljive u obliku tzv. stanja sistema skalarnih diferencijalnih jednačina.

$F_{x p}, F_{y p}$ i $F_{z p}$ predstavljaju oznake za komponente spoljašnjih sila duž osa polubrzinskog KS. Dati sistem jednačina (3), uz određivanje početnih uslova, dovoljan je za proračun dinamike leta rakete sa blokiranim upravljajućim površinama ili sa njihovim programskim otklanjanjem.

\section{Model aerodinamike rakete}

Osobine aerodinamičkih sila i momenata, kao funkcija napadnih uglova rakete i uglova otklona upravljačkih površina, zavise od tipa simetrije rakete, koja je opet funkcija rasporeda nosećih površina rakete. Simulacioni model aerodinamike rakete strukturno čine ulazne i izlazne veličine.

Ulazne veličine:

- kinematske veličine (trenutne vrednosti napadnih uglova $\alpha$ i $\beta$, izvoda napadnih uglova $\dot{\alpha}$ i $\dot{\beta}$, ugaonih brzina rakete $\omega_{\mathrm{x}}, \omega_{\mathrm{y}}, \omega_{\mathrm{z}}$, te linearnih brzina $\left.\mathrm{u}, \mathrm{v}, \mathrm{w}\right)$;

- otkloni upravljačkih površina (trenutne vrednosti $\delta_{\mathrm{h}}$ i $\delta_{\mathrm{v}}$, i njihovih izvoda $\dot{\delta}_{\mathrm{h}}$ i $\dot{\delta}_{\mathrm{v}}$ );

- parametri atmosfere (gustina vazduha $\rho$, pritisak $p_{a} i$ temperatura $T_{a}$ ).

Izlazne veličine:

- komponente aerodinamičkih sila i momenata (u vezanom koordinatnom sistemu);

- šarnirni momenti (aerodinamičko opterećenje upravljačkih površina).

Komponente aerodinamičke sile na ose vezanog koordinatnog sistema (aero- dinamička uzdužna, poprečna i normalna sila) mogu se dobiti kao:

$$
\left|\begin{array}{l}
X \\
Y \\
Z
\end{array}\right|=\left|\begin{array}{l}
\frac{1}{2} C_{x} \rho V_{a}^{2} S \\
\frac{1}{2} C_{y} \rho V_{a}^{2} S \\
\frac{1}{2} C_{z} \rho V_{a}^{2} S
\end{array}\right|
$$

gde su:

$\mathrm{C}_{\mathrm{x}}, \mathrm{C}_{\mathrm{y}}, \mathrm{C}_{\mathrm{z}}$ - bezdimenzionalni (aerodinamički) koeficijenti,

$\rho$ - gustina vazduha $\left[\mathrm{kg} / \mathrm{m}^{3}\right]$,

$\mathrm{V}_{\mathrm{a}}$ - brzina leta $\mathrm{u}$ odnosu na vazduh $\left[\mathrm{ms}^{-1}\right]$,

S - karakteristična površina (obično poprečni presek tela rakete $\left.\left[\mathrm{m}^{2}\right]\right)$.

Komponente aerodinamičkog momenta duž osa vezanog koordinatnog sistema (momenat valjanja, propinjanja i skretanja) su:

$$
\left|\begin{array}{l}
M_{x} \\
M_{y} \\
M_{z}
\end{array}\right|=\left|\begin{array}{l}
\frac{1}{2} C_{l} \rho V_{a}^{2} S b \\
\frac{1}{2} C_{m} \rho V_{a}^{2} S c \\
\frac{1}{2} C_{n} \rho V_{a}^{2} S b
\end{array}\right|
$$

gde su:

$\mathrm{C}_{\mathrm{l}}, \mathrm{C}_{\mathrm{m}}, \mathrm{C}_{\mathrm{n}}$ - bezdimenzionalni (aerodinamički) koeficijenti,

c - raspon krila rakete,

b - srednja aerodinamička tetiva.

Umesto komponenata aerodinamičke sile duž osa vezanog KS, uobičajeno je da se posmatraju njene komponente duž osa brzinskog KS, odnosno polubrzinskog KS. U brzinskom KS kompo- 
nente aerodinamičke sile su: $X_{B}$ - sila otpora, $Y_{B}-$ sila uzgona, $Z_{B}$ - bočna sila (sila klizanja). Sve deluju u negativnom smeru odnosnih osa vezanog KS.

Komponente aerodinamičke sile u polubrzinskom KS su, prema tome:

$$
\left|\begin{array}{l}
X_{p} \\
Y_{p} \\
Z_{p}
\end{array}\right|=\left|\begin{array}{l}
-X_{B} \\
Y_{B} \cos \gamma_{c}-Z_{B} \sin \gamma_{c} \\
Y_{B} \sin \gamma_{c}+Z_{B} \cos \gamma_{c}
\end{array}\right|
$$

Dakle, aerodinamička sila i aerodinamički momenat nastaju kao posledica međusobnog delovanja rakete i vazdušne sredine. Prvenstveno zavise od brzine rakete, gustine vazduha (tj. visine leta), geometrije rakete, položaja rakete prema struji vazduha i karakteristika upravljačkih površina. Aerodinamički koeficijenti $\mathrm{u}$ osnovi zavise od oblika rakete, njene orijentacije u odnosu na struju vazduha, te od kriterijuma aerodinamičke sličnosti (Mahovog broja $\mathrm{M}=\frac{\mathrm{V}_{\mathrm{v}}}{\mathrm{a}}$ i Rejnaldsovog broja $\mathrm{Re}=\frac{\mathrm{V}_{\mathrm{v}} \mathrm{b}}{\mathrm{v}}$, gde je a - brzina prostiranja zvuka u vazduhu, $v$ - kinematski koeficijent viskoznosti vazduha $\mathrm{i} \mathrm{V}_{\mathrm{v}}-$ brzina rakete u odnosu na vazduh). Određivanje aerodinamičkih koeficijenata je aproksimativno, pri čemu se u obzir uzima poremećajno kretanje tela rakete $u$ okolini nominalne trajektorije duž koje postoji ravnoteža svih spoljnih sila i momenata. Pretpostavka o srazmerno malim poremećajima u okolini nominalne trajektorije omogućava primenu postupka linearizacije, odnosno aproksimacije nelinearnih zavisnosti aerodinamičkih koeficijenata od kinematskih parametara, razvojem u Tejlorov niz:

$$
\begin{aligned}
& C\left(k_{1}, k_{2}, \ldots, k_{n}\right) \cong \frac{\partial C}{\partial k_{1}} \Delta k_{1}+\frac{\partial C}{\partial k_{2}} \Delta k_{2}+ \\
& +\ldots+\frac{\partial C}{\partial k_{n}} \Delta k_{n}
\end{aligned}
$$

gde su:

$C$ - aerodinamički koeficijent (nelinearno zavisan od kinematskih parametara $\mathrm{k}_{\mathrm{i}}, \mathrm{i}=$ $1, \ldots, n)$,

$\frac{\partial \mathrm{C}}{\partial \mathrm{k}_{\mathrm{i}}}$ - aerodinamički derivativ - parcijalni izvod aerodinamičkog koeficijenta $\mathrm{C}$ po kinematskoj veličini $\mathrm{k}_{\mathrm{i}}$, izračunat $\mathrm{za}$ nominalne vrednosti parametara,

$\Delta \mathrm{k}_{\mathrm{i}}$ - odstupanje kinematskog parametra u okolini nominalne veličine.

Svaki od aerodinamičkih koeficijenata zavisi od određenih kinematskih parametara, tako da se neki mogu zanemariti. Zanemarenja su moguća ne samo zbog zanemarive veličine aerodinamičkog derivata, već i množenja sa drugim malim veličinama, čime je ukupan doprinos u aerodinamičkom koeficijentu zanemariv. Proračun aerodinamičkih koeficijenata vrši se uz pretpostavku o malim napadnim uglovima. Pod malim uglovima smatra se onaj opseg napadnih uglova za koje važi: aerodinamički koeficijenti osnosimetrične konfiguracije krilo-telo ne zavise od orijentacije rakete (kružna simetrija) i linearne su funkcije napadnog ugla i otklona upravljačkih površina. Da bi ovaj uslov bio zadovoljen, potrebno je da su aerodinamički koeficijenti izolovanih elemenata (telo, upravljačke površine - krmila) linearna funkcija napadnog ugla, što znači da ne dolazi do odvajanja vrtloga sa tela i prednje ivice nosećih površina, ili je uti- 
caj ovih vrtloga zanemariv, te je uticaj vrtloga koji se odvajaju sa zadnje ivice krmila (upravljajuće površine) ili tela na zadnju kombinaciju mali. Opseg malih napadnih uglova moguće je dovoljno tačno odrediti jedino eksperimentalno. U literaturi se u tu svrhu obično preporučuje i posmatra oblast od $5^{\circ}$ do $6^{\circ}$. Naime, sile na kombinaciji krilo-telo, usled vrtloga koji se odvajaju sa zadnje ivice krmila, istog su reda veličine kao i sile izolovanih elemenata, te se ne mogu zanemariti. Po svojoj prirodi, ove su sile nelinearne funkcije napadnog ugla, što je i uzrok nelinearnosti aerodinamičkih koeficijenata rakete. Pretpostavka da su $\mathrm{u}$ referentnom kretanju kinematički parametri i uglovi otklona upravljačkih površina dovoljno male veličine $u$ većini slučajeva nije gruba, posebno za rakete kod kojih je izvršena stabilizacija valjanja i čija trajektorija leži u granicama relativno malog prostornog ugla. Referentnom trajektorijom naziva se teorijska trajektorija sa nominalnim vrednostima parametara rakete i sistema upravljanja, zadatim početnim uslovima, definisanim manevrom cilja, standardnim parametrima atmosfere itd. Realna trajektorija uvek se razlikuje od teoretske, ne samo po tome što se dinamičke osobine rakete i SULR opisuju jednačinama samo približno, već i kao rezultat delovanja niza slučajnih faktora na raketu i SULR kao poremećajima kretanja. Referentno kretanje, koje uzima u obzir delovanje različitih vidova poremećaja, naziva se poremećajnim. Obično se u linearizaciji zanemaruje uticaj prirasta visine leta rakete y na aerodinamičke sile $\mathrm{i}$ momente, jer je taj uticaj veoma mali. Aerodinamički koeficijenti mogu se iz- računati $\mathrm{u}$ funkciji totalnog napadnog ugla, ugla orijentacije projektila, ugla ravni upravljanja, rezultujućeg ugla otklona upravljačkih površina - kada su u pitanju doprinosi statičkih sila i u funkciji ugaonih brzina - kada su u pitanju doprinosi dinamičkih sila. Osim ,selekcije“ aerodinamičkih derivata, treba uzeti u obzir zavisnost aerodinamičkih derivata od Mahovog broja. Ova zavisnost određuje se eksperimentalno (interpolacijom mernih tačaka) ili proračunom. Usvaja se da je ova zavisnost poznata (zadata tablično, iz koje se za trenutnu brzinu rakete zavisnost izračunava linearnom interpolacijom između dve najbliže vrednosti).

Sistemi jednačina (4) i (5) mogu se predstaviti na sledeći način:

$$
\left|\begin{array}{l}
X \\
Y \\
Z
\end{array}\right|=\left|\begin{array}{l}
\frac{1}{2} \rho V_{a}^{2} S C_{x}\left(y, V, \alpha, \beta, \delta_{v}, \delta_{h}\right) \\
\frac{1}{2} \rho V_{a}^{2} S C_{y}\left(y, V, \alpha, \delta_{v}\right) \\
\frac{1}{2} \rho V_{a}^{2} S C_{z}\left(y, V, \beta, \delta_{h}\right)
\end{array}\right|
$$

odnosno,

$$
\left|\begin{array}{l}
M_{x} \\
M_{y} \\
M_{z}
\end{array}\right|=\left|\begin{array}{l}
\frac{1}{2} \rho V_{a}^{2} S b C_{1} \\
\left(y, V, \alpha, \beta, \delta_{h}, \delta_{e}, \omega_{x}, \omega_{y}, \omega_{z}\right) \\
\frac{1}{2} \rho V_{a}^{2} S_{c} C_{m} \\
\left.y, V, \alpha, \delta_{v}, \omega_{z}, \dot{\alpha}, \dot{\delta}_{v}\right) \\
\frac{1}{2} \rho V_{a}^{2} S b C_{n} \\
\left.y, V, \beta, \delta_{h}, \omega_{x}, \omega_{y}, \dot{\beta}, \dot{\delta}_{\mathrm{h}}\right)
\end{array}\right|
$$


Razvojem u Tejlorov niz, u kojem se mogu sačuvati članovi drugog reda, uz pretpostavku o sporo promenljivim veličinama visine y $\mathrm{i}$ brzine rakete $\mathrm{V}_{\mathrm{R}}$, (u odnosu na ostale kinematske parametre), sada se može pisati:

$$
\left|\begin{array}{l}
X \\
Y
\end{array}\right|=\left|\begin{array}{l}
\frac{1}{2} \rho V_{a}^{2} S\left(\begin{array}{l}
C_{x 0}+C_{x}^{\alpha^{2}} \alpha^{2}+ \\
+C_{x}^{\alpha \delta_{v}} \alpha \delta_{v}+C_{x}^{\delta_{v}^{2}} \delta_{v}^{2}+ \\
+C_{x}^{\beta^{2}} \beta^{2}+C_{x}^{\beta \delta_{h}} \beta \delta_{h}+C_{x}^{\delta_{h}^{2}} \delta_{h}^{2}
\end{array}\right) \\
\frac{1}{2} \rho V_{a}^{2} S\left(C_{y}^{\beta} \beta+C_{y}^{\dot{\beta}} \dot{\beta}+C_{y}^{\omega_{z}} \omega_{z}+C_{y}^{\delta_{h}} \delta_{h}\right) \\
\frac{1}{2} \rho V_{a}^{2} S\left(C_{z}^{\alpha} \alpha+C_{z}^{\dot{\alpha}} \dot{\alpha}+C_{z}^{\omega_{y}} \omega_{y}+C_{z}^{\delta_{v}} \delta_{v}\right)
\end{array}\right|
$$

odnosno,

$$
\left|\begin{array}{l}
M_{x} \\
M_{y} \\
M_{z}
\end{array}\right|=\left|\begin{array}{l}
\frac{1}{2} \rho V_{a}^{2} S b\left(\begin{array}{l}
C_{l}^{\omega_{x}} \omega_{x}+C_{l}^{\omega_{y}} \omega_{y}+ \\
+C_{l}^{\omega_{z}} \omega_{z}+C_{l}^{\alpha} \omega_{\alpha}+C_{l}^{\beta} \omega_{\beta} \\
+C_{l}^{\delta_{e}} \delta_{e}+C_{l}^{\delta_{h}} \delta_{h}+C_{l}^{\delta_{v}} \delta_{v}
\end{array}\right) \\
\frac{1}{2} \rho V_{a}^{2} S c\left(\begin{array}{l}
C_{m}^{\alpha} \alpha+C_{m}^{\dot{\alpha}} \dot{\alpha}+C_{m}^{\omega_{x}} \omega_{x}+ \\
+C_{m}^{\omega_{y}} \omega_{y}+C_{m}^{\delta_{v}} \delta_{v}+C_{m}^{\dot{\delta}_{v}} \dot{\delta}_{v}
\end{array}\right) \\
\frac{1}{2} \rho V_{a}^{2} S b\left(\begin{array}{l}
C_{n}^{\beta} \beta+C_{n}^{\dot{\beta}} \dot{\beta}+C_{n}^{\omega_{x}} \omega_{x}+ \\
+C_{n}^{\omega_{z}} \omega_{z}+C_{n}^{\delta_{h}} \delta_{h}+C_{n}^{\dot{\delta}_{h}} \dot{\delta}_{h}
\end{array}\right)
\end{array}\right|
$$

Od navedenih aerodinamičkih koeficijenata, u jednačinama (10) i (11), za slučaj osnosimetrične rakete, posmatraju se sledeći koeficijenti:

- koeficijent sile otpora $\mathrm{C}_{\mathrm{x}}$ :
$C_{x}=C_{x 0}+C_{x i}$

gde su:

$\mathrm{C}_{\mathrm{x} 0}$ - koeficijent otpora za nulte vrednosti $\alpha=\delta_{\mathrm{v}}=0$,

$\delta_{\mathrm{v}}-$ ekvivalentni otklon upravljajućih površina, kojim se stvara upravljački momenat oko ose $\mathrm{O}_{\mathrm{y}}$ vezanog koordinatnog sistema,

$\mathrm{C}_{\mathrm{xi}}$ - koeficijent indukovanog otpora:

$C_{x i}=C_{x}^{\alpha^{2}} \alpha^{2}+C_{x}^{\alpha \delta_{v}} \alpha \delta_{v}+C_{x}^{\delta_{v}^{2}} \delta_{v}^{2}$

- koeficijent bočne sile $C_{z}$ :

$C_{z}=C_{z}^{\beta} \beta+C_{z}^{\dot{\beta}} \dot{\beta}+C_{x}^{\omega_{z}} \omega_{z}+C_{y}^{\delta_{v}} \delta_{v}$

- koeficijent bočne sile $\mathrm{C}_{\mathrm{y}}$ :

$C_{y}=C_{y}^{\alpha} \alpha+C_{y}^{\dot{\alpha}} \dot{\alpha}+C_{y}^{\omega_{y}} \omega_{y}+C_{y}^{\delta_{v}} \delta_{v}$

Jednačine (14) i (15) su identične, s obzirom na to da kod osnosimetrične rakete postoji potpuna aerodinamička simetrija. Osnovni doprinos aerodinamičkom koeficijentu sile uzgona, u jednačini (15), potiče od krila, trupa i upravljačkih površina i izražen je članom $\mathrm{C}_{\mathrm{y}}^{\alpha} \alpha$, a dopunski doprinos potiče od otklona odnosnih upravljačkih površina i izražen je članom $\mathrm{C}_{\mathrm{y}}^{\delta_{\mathrm{v}}} \delta_{\mathrm{v}}$ (obično je za red veličine manji od $\left.C_{y}^{\alpha} \alpha\right)$. Članovi $C_{y}^{\dot{\alpha}} \dot{\alpha} \quad$ i $\quad C_{y}^{\omega_{y}} \omega_{y}$ aktuelni su $\mathrm{u}$ toku prelaznog procesa $\mathrm{i}$ predstavljaju funkciju aerodinamičkog prigušenja pri letu u vertikalnoj ravni (uzdužno kretanje, kretanje oko ose $\mathrm{O}_{\mathrm{x}}$ 
vezanog KS). Ove članove moguće je izraziti kao:

$$
\begin{aligned}
& C_{y}^{\dot{\alpha}}=\frac{c}{l_{s}} C_{m}^{\dot{\alpha}} \\
& C_{y}^{\omega_{y}}=\frac{c}{l_{s}} C_{m}^{\omega_{y}}
\end{aligned}
$$

gde su:

$\mathrm{C}_{\mathrm{m}}^{\dot{\alpha}}$ i $_{\mathrm{m}}^{\omega_{\mathrm{y}}}$ - prigušni koeficijenti za aerodinamički stabilnu raketu (negativnog predznaka),

$1_{\mathrm{s}}$ - udaljenost šarnirne ose krmila od centra mase rakete.

Identičnost doprinosa bočnoj sili je potpuna, s obzirom na potpunost aerodinamičke simetrije osnosimetrične rakete, uz odgovarajuće ose.

- koeficijent momenta valjanja $\mathrm{C}_{1}$ :

$$
\begin{aligned}
& C_{l}=C_{l}^{\omega_{x}} \omega_{x}+C_{l}^{\omega_{y}} \omega_{y}+C_{l}^{\omega_{z}} \omega_{z}+ \\
& +C_{l}^{\alpha} \alpha+C_{l}^{\beta} \beta+C_{l}^{\delta_{e}} \delta_{e}+C_{l}^{\delta_{h}} \delta_{h}+C_{l}^{\delta_{v}} \delta_{v}
\end{aligned}
$$

Treba napomenuti da je u koeficijentu momenta valjanja $C_{l}$ dominantan uticaj momenta elerona $\delta_{\mathrm{e}} \mathrm{i}$ prigušnog člana $C_{1}^{\omega_{x}}$ (zavisnost momenta oko podužne ose rakete od brzine rotacije oko iste ose), dok su uticaji ostalih članova od sekundarnog značaja (pokazuju kuplovanja kanala upravljanja na kanal valjanja).

- koeficijent momenta propinjanja $\mathrm{C}_{\mathrm{m}}$ :

$$
\begin{aligned}
C_{m}= & C_{m}^{\alpha} \alpha+C_{m}^{\dot{\alpha}} \dot{\alpha}+C_{m}^{\omega_{y}} \omega_{y}+ \\
& +C_{m}^{\delta_{v}} \delta_{v}+C_{m}^{\dot{\delta}_{v}} \dot{\delta}_{v}
\end{aligned}
$$

dominantan je uticaj u stvaranju momenta propinjanja osnovne komponente uzgonske sile, odnosno član $\mathrm{C}_{\mathrm{m}}^{\alpha} \alpha$. Derivativ $\mathrm{C}_{\mathrm{m}}^{\delta \mathrm{v}}$ predstavlja doprinos uzgonske sile krmila visine $\delta_{v}$, dok ostali derivativi predstavljaju doprinos prigušnog momenta (negativnog predznaka) rakete. Statičke karakteristike rakete definisane su odnosom osnovne komponente uzgonske sile i uzgonske sile krmila visine, odnosno:

$$
\frac{\alpha}{\delta_{v}}=\frac{C_{m}^{\delta_{v}}}{C_{m}^{\alpha}}
$$

Takođe, veza derivata $C_{y}^{\alpha}$ i $C_{m}^{\alpha}$ :

$$
C_{m}^{\alpha}=\left(X_{C P}-X_{C M}\right) C_{y}^{\alpha}
$$

gde su:

$\mathrm{X}_{\mathrm{CP}}$ - koordinata centra pritiska ( $\mathrm{u}$ odnosu na vrh rakete),

$\mathrm{X}_{\mathrm{CM}}$ - koordinata centra mase ( $\mathrm{u}$ odnosu na vrh rakete).

- koeficijent momenta propinjanja $\mathrm{C}_{\mathrm{n}}$ :

$$
\begin{aligned}
C_{n}= & C_{n}^{\beta} \beta+C_{n}^{\dot{\beta}} \dot{\beta}+C_{n}^{\omega_{z}} \omega_{z}+C_{n}^{\delta_{h}} \delta_{h}+ \\
& +C_{n}^{\dot{\delta}_{h}} \dot{\delta}_{h}
\end{aligned}
$$

Vidljivo je da su doprinosi derivata iz jednačina (16) i (18) zbog osne simetrije rakete istovetni, odnosno:

$$
\begin{aligned}
& C_{m}^{\alpha}=C_{n}^{\beta} ; \quad C_{m}^{\dot{\alpha}}=C_{n}^{\dot{\beta}} ; \quad C_{m}^{\omega_{y}}=C_{n}^{\omega_{z}} ; \\
& C_{m}^{\delta_{v}}=C_{n}^{\delta_{h}} \delta_{k} ; C_{m}^{\dot{\delta}_{v}}=C_{n}^{\dot{\delta}_{h}} .
\end{aligned}
$$

- šarnirni momenti 




Sl. 3 - Nastajanje momenta na upravljivoj aerodinamičkoj površini:

$O$ - osa obrtanja krila, $C P$ - centar pritiska aerodinamičkih sila, $N$ - normalna komponenta aerodinamičkih sila, koje deluju na krmilo, $h$-rastojanje centra pritiska od ose obrtanja krmila, $\alpha$-napadni ugao krmila, $\delta$-ugao zakretanja krmila

Konzola svake od upravljačkih površina čvrsto je spojena upravljačkim vratilom. Osa ovog vratila naziva se šarnirnom osom. Momenti aerodinamičkih sila koje deluju na upravljačkim površinama za šarnirnu osu su šarnirni momenti upravljačkih površina (sl. 3), a nastaju kao posledica dejstva aerodinamičkog opstrujavanja, koje deluje na krmilo, u tački van obrtanja krmila.

Šarnirni momenti nastaju od opterećenja upravljajućih površina aerodinamičkim silama oko šarnirne ose (osa rotacije upravljajuće površine). Iako direktno ne figuriraju $u$ jednačinama kretanja rakete, njihov uticaj na dinamiku sistema upravljanja je bitan.

U opštem slučaju, koeficijent šarnirnog momenta je:

$$
C_{s}=C_{s 0}+C_{s}^{\alpha} \alpha+C_{s}^{\delta} \delta_{k}+C_{s}^{\dot{\delta}} \dot{\delta}_{k}
$$

gde je $\delta_{\mathrm{k}}(\mathrm{k}=1,2,3,4)$ broj krmila.

Koeficijent $\mathrm{C}_{\mathrm{s} 0}$ predstavlja doprinos šarnirnom momentu usled ugradnje krmila na neutralnom položaju, što je $\mathrm{u}$ modelu pretpostavljeno, tj. za $\alpha=0$ i $\delta=0$. Pored razmatranih šarnirnih momenata koji deluju na pokretač krmila, u toku kretanja javlja se i moment sile trenja. On se može predstaviti zbirom momenta suvog trenja $\mathrm{u}$ osi vratila krmila $\mathrm{M}_{\text {tr }}(\dot{\delta})$ i momenta viskoznog trenja $\mathrm{K}_{\mathrm{f}} \dot{\delta} \quad\left(\mathrm{K}_{\mathrm{f}}-\right.$ koeficijent viskoznog trenja) aerodinamičkog strujanja. Dakle, član $\mathrm{C}_{\mathrm{s}}^{\dot{\delta}}$ predstavlja prigušni član i moguće ga je zanemariti, što je u modelu i učinjeno. Veličine pojedinih članova zavise od klase rakete i uslova leta, a važno ih je odrediti radi utvrđivanja potrebne snage pokretača krmila i analize uticaja svakog od članova u koeficijentu šarnirnog momenta na dinamičke osobine pokretača krmila. S obzirom na usvojeni raspored upravljajućih površina (krmila), odnosno konfiguraciju (X), smerove dejstva aerodinamičkih sila moguće je predstaviti kao na slici 4.

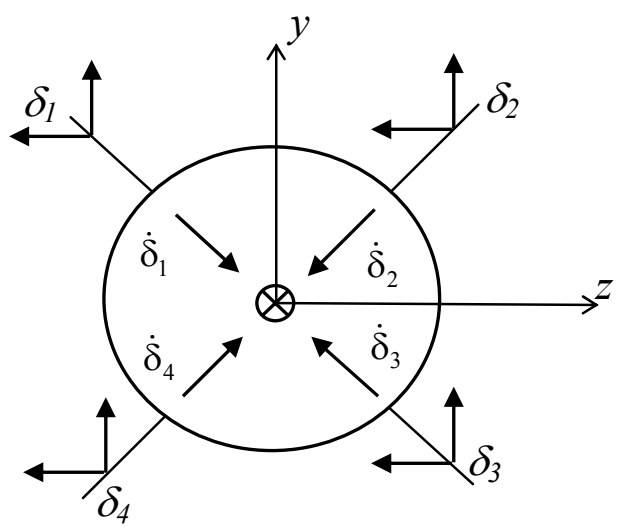

Sl. 4 - Smerovi dejstva aerodinamičkih sila na krmilima rakete $(X)$ konfiguracije 
Orijentacija aerodinamičkih sila na slici 4 uzeta je za pozitivne smerove napadnog ugla rakete $\alpha$, odnosno ugla klizanja rakete $\beta$. Za usvojene oznake krmila, smerove rotacije krmila i uz pretpostavku da je lokalni centar pritiska iza šarnirne ose, koeficijenti šarnirnih momenata računaju se jednačinama:

$$
\left|\begin{array}{l}
C_{s_{1}} \\
C_{s_{2}} \\
C_{s_{3}}
\end{array}\right|=\left|\begin{array}{l}
C_{s}^{\alpha} \frac{\sqrt{2}}{2}(\beta-\alpha)+C_{s}^{\delta} \delta_{1} \\
C_{s}^{\alpha} \frac{\sqrt{2}}{2}(\alpha+\beta)+C_{s}^{\delta} \delta_{2} \\
C_{s}^{\alpha} \frac{\sqrt{2}}{2}(\alpha-\beta)+C_{s}^{\delta} \delta_{3} \\
C_{s}^{\alpha} \frac{\sqrt{2}}{2}(-\alpha-\beta)+C_{s}^{\delta} \delta_{4}
\end{array}\right|
$$

Šarnirni moment računa se po relaciji:

$$
M_{s_{k}}=C_{s_{k}} \frac{1}{2} \rho V^{2} S_{k} b_{k}
$$

gde su:

$\mathrm{S}_{\mathrm{k}}-$ karakteristična površina krmila i

$b_{k}$ - srednja aerodinamička tetiva krmila.

U zavisnosti od Ma broja, određenog eksperimentalno ili proračunom, tabelarno su prikazane vrednosti aerodinamičkih derivativa, a za potrebe simulacije leta određuju se vrednosti derivativa linearnom interpolacijom. Tako izračunati derivativi služe za izračunavanje aerodinamičkih koeficijenata (na osnovu trenutnih vrednosti kinematskih parametara), a na osnovu njih i za izračunavanje tekućih vrednosti gustine vazduha i brzine rakete, te aerodinamičke sile i momenata duž odnosnih snaga vezanog KS. Za formiranje diferencijalnih jednačina, koje opisuju kretanje rakete (3), tako dobijene aerodinamičke sile i momenti projektuju se na ose polubrzinskog KS.

\section{Model poremećaja rakete $u$ letu}

Osim poremećaja koji nastaje usled nepotpune kolinearnosti vektora sile potiska, u letu se, usled grešaka pri ugradnji nosećih površina rakete (krila) i upravljajućih površina rakete (krmila), javljaju poremećaji sličnog karaktera. S obzirom na to da promašaj kod samonavođenih raketa raste sa porastom ugaone brzine valjanja (oko podužne ose), važno je simulirati poremećajni momenat valjanja, prouzrokovan nesimetričnom ugradnjom krila. Shodno jednačinama (5) i (18), i ovaj momenat može se predstaviti u vezanom koordinatnom sistemu:

$M_{x_{p o r}}=\frac{1}{2} C_{l}^{\varepsilon} \varepsilon_{k} \rho V^{2} S b$

gde su:

$\mathrm{C}_{1}^{\varepsilon}$ - aerodinamički derivativi,

$\varepsilon_{\mathrm{k}}$ - ugao izazvan greškom ugradnje krila rakete.

Od spoljašnjih poremećaja najkarakterističniji su oni koji su nastali dejstvom vetra i turbulencija atmosfere [7].

\section{Model autopilota}

Autopilot je sistem sa povratnom spregom, koji predstavlja unutrašnju spregu glavne petlje vođenja. Izuzimajući uticaj sile gravitacije (u vertikalnoj ravni), za rakete sa dve ravni simetrije 
autopiloti se mogu smatrati identičnim i nazivaju se bočnim autopilotima. Autopiloti koji služe za upravljanje oko glavne ose inercije ili za stabilizaciju rotacije oko te ose nazivaju se autopilotima valjanja. Autopiloti se mogu klasifikovati na sledeći način:

\begin{tabular}{|l|l|l|}
\hline \multicolumn{3}{|c|}{ A u t o p i l o t i } \\
\hline $\begin{array}{c}\text { Za stabilizaciju } \\
\text { valjanja }\end{array}$ & \multicolumn{1}{|c|}{ Bočni } & \multicolumn{1}{c|}{ Specijalni } \\
\hline \multirow{2}{*}{$\begin{array}{l}\text { stabilizacija ugla } \\
\text { valjanja }\end{array}$} & $\begin{array}{l}\text { sa dva } \\
\text { akcelerometra }\end{array}$ & ručni sistem vođenja \\
\cline { 2 - 3 } & $\begin{array}{l}\text { sa brzinskim } \\
\text { žiroskopom }\end{array}$ & $\begin{array}{l}\text { sistem vertikalnog } \\
\text { lansiranja }\end{array}$ \\
\hline \multirow{2}{*}{$\begin{array}{l}\text { stabilizacija ugaone } \\
\text { brzine valjanja }\end{array}$} & $\begin{array}{l}\text { sa akcelerome- } \\
\text { trom i brzin- } \\
\text { skim žirosko- } \\
\text { pom }\end{array}$ & $\begin{array}{l}\text { sistemi koji lete iznad } \\
\text { same površine mora i } \\
\text { na konstantnoj visini }\end{array}$ \\
\cline { 3 - 3 } & $\begin{array}{l}\text { upravljanje azimutom u } \\
\text { inercijalnom smislu }\end{array}$ \\
\hline
\end{tabular}

Kombinacija akcelerometra u kanalu upravljanja rakete, preko kojega se ostvaruje glavna povratna sprega rakete, te brzinskog žiroskopa (za prigušenje), najčešće je korišćena u sistemima samonavođenja. Akcelerometar se smešta bitno ispred centra gravitacije, obično na rastojanju od polovine ili dve trećine rastojanja centra gravitacije od vrha rakete. Brzinski žiroskop smešta se na mesto gde je ugaono kretanje, usled vibracija rakete, najmanje. Na slici 5 prikazana je konfiguracija autopilota $u$ formi funkcije prenosa $n_{z d}$ i $n_{z}$ (zahtevano i stvarno bočno ubrzanje centra gravitacije rakete, respektivno), gde su:

Ks - pojačanje servosistema pokretača krmila [rad/s];

$\mathrm{Kg}$ - pojačanje brzinskog žiroskopa $[\mathrm{V} / \mathrm{rad} / \mathrm{s}]$;

c - udaljenost ose osetljivosti akcelerometra od centra gravitacije;

$\mathrm{G}_{\delta_{\mathrm{k}}}^{\mathrm{n}_{\mathrm{z}}}(\mathrm{s})$ i $\mathrm{G}_{\mathrm{n}_{\mathrm{z}}}^{\omega_{\mathrm{y}}}(\mathrm{s})$ - funkcije prenosa bočnog ubrzanja $\mathrm{n}_{\mathrm{z}}(\mathrm{s})$ i ugaone brzine $\omega_{\mathrm{y}}(\mathrm{s})$.

Pojačanje servosistema pokretača krmila je sa negativnim predznakom, pošto funkcija prenosa $G_{\delta_{k}}^{n_{z}}(s)$ ima negativno pojačanje.

Sa slike 5 uočava se da je funkcija spregnutog prenosa sa zatvorenom povratnom spregom:

$$
G(s)=\frac{n_{z}}{n_{z d}}=\frac{-n_{1} s^{2}+n_{1} s+n_{3}}{a_{4} s^{4}+a_{3} s^{3}+a_{2} s^{2}+a_{1} s+a_{0}}
$$

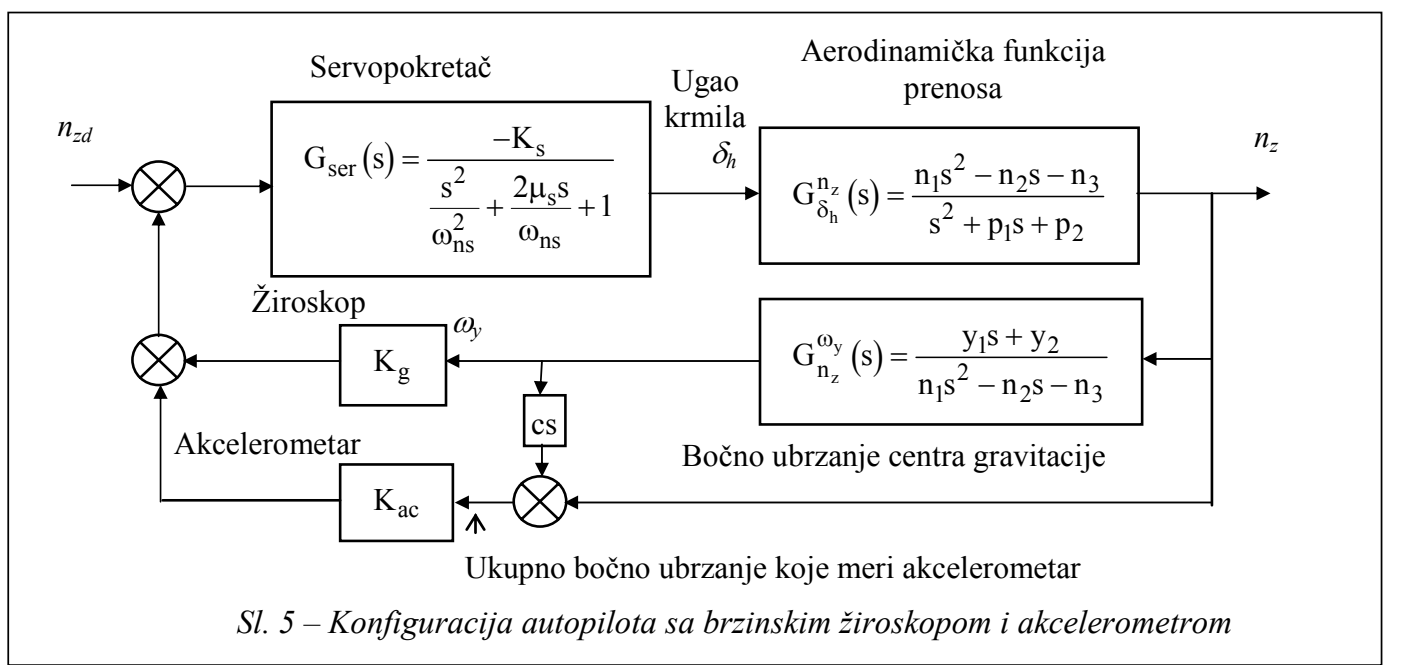


$\frac{n_{z}}{n_{z d}}=\frac{G_{s e r}(s) G_{d_{k}}^{n_{z}}(s)}{1+G_{s e r}(s) G_{\delta_{k}}^{n_{z}}(s) G_{p v}(s)}$

$$
G_{p v}(s)=K_{g} G_{n_{z}}^{\omega_{y}}(s)+K_{a c}\left[1+c s G_{n_{z}}^{\omega_{y}}(s)\right]
$$

pa kako $a_{1}$ bitno zavisi od koeficijenta $\mathrm{K}_{\mathrm{g}}$, za suviše veliko $K_{g}$ sistem može biti nestabilan. Nestabilnost se može pojaviti pri stvarno velikom prigušenju krmila (povećavajući vrednost $\mathrm{a}_{3}$ ). Promenom brzine leta rakete menjaju se dinamički

$$
\frac{n_{z}}{n_{z d}}=\frac{-K_{s}\left(n_{1} s^{2}-n_{1} s-n_{3}\right)}{\left(\frac{s^{2}}{\omega_{n s}^{2}}+\frac{2 \mu_{s}}{\omega_{n s}}+1\right)\left(s^{2}+p_{1} s+p_{2}\right)+K_{g}+K_{a c} c s\left(y_{1} s+y_{2}\right)+K_{a c}\left(n_{1} s^{2}-n_{2} s-n_{3}\right)}
$$

gde su $\mathrm{n}_{1}, \mathrm{n}_{2}, \mathrm{n}_{3}, \mathrm{p}_{1}, \mathrm{p}_{2}, \mathrm{y}_{1} \mathrm{i} \mathrm{y}_{2}$ - dinamički koeficijenti, koji zavise od dinamičkog pritiska i aerodinamičkih koeficijenata.

Da bismo projektovali autopilot za raketu sa upravljačkim površinama smeštenim na njenom repnom delu, potrebno je prvo proceniti zahtevane (potrebne) aerodinamičke derivate, za usvojenu brzinu leta rakete. Ako pretpostavimo projektovanje bočnog autopilota bez kompenzacije, moguća je optimizacija parametara servosistema krmila $K_{s}, \omega_{n s}$ i $\mu$, odnosno žiroskopa $i$ akcelerometra $\mathrm{K}_{\mathrm{g}}, \mathrm{K}_{\mathrm{a}}$. Pojačanje zatvorene povratne sprege ne bi trebalo da se menja preko $\pm 10 \%$. Neophodni stepen stabilnosti, procentualni preskok u vremenskom domenu i rezerva pojačanja te faze $u$ frekventnom domenu, moguće je odrediti iz funkcionalnih zahteva. Da bi se izbeglo zasićenje brzine krmila u prisustvu šuma potrebno je manje pojačanje i uži propusni opseg servosistema. Da bi sistem bio stabilan po RutHarvicovom kriterijumu, koeficijenti funkcije spregnutog prenosa moraju zadovoljiti uslov:

$a_{1}\left(a_{2} a_{3}-a_{1} a_{4}\right)>a_{0} a_{3}^{2}$ koeficijenti koji ulaze u funkciju prenosa, a time se menja i odziv celog sistema upravljanja. Koeficijent gušenja dominantnih modova raste sa udaljavanjem akcelerometra od centra gravitacije (ka nosu rakete), a stepen stabilnosti povećava se propuštanjem kroz diferencijalni uskladnik signala sa brzinskog žiroskopa, odnosno faznim pomeranjem unapred. Kola za prednjačenje faze i fazno kašnjenje su uskladnici i efikasni su jedino ako su njihove vremenske konstante $u$ vezi sa frekventnim područjem otvorene sprege. Ako bi pojačanje otvorene sprege značajno variralo, kolo kompenzacije može poboljšati odziv na jednom ekstremnom pojačanju, odnosno pogoršati ga na drugom. U opštem slučaju, praktično je neizvodljivo uvođenje pozitivnog faznog pomaka u signal greške jer je ulaz u autopilot fazno pomeren unapred u glavnoj sprezi vođenja. Izlaz akcelerometra se, u opštem slučaju, vodi na diferencijalni kompenzator. Bočno ubrzanje, nastalo od normalnih sila, javlja se uvek. Dodatno kretanje tela rakete može nastati od aerodinamičkih šumova i šumova u sili potiska motora rakete. Zatvaranjem instrumentalne povratne sprege moguće je poboljšanje 
vremenskog odziva tela rakete, a takođe i znatne promene u uticaju aerodinamičkog ponašanja.

\section{Autopilot za stabilizaciju ugla valjanja}

Ugaona brzina valjanja rakete dovodi do pojave unakrsnih veza između bočnih kanala upravljanja i kanala valjanja, što bitno utiče na proces samonavođenja. Smanjenje uticaja unakrsnih veza zahteva ograničenje brzine valjanja rakete. Zadatak sistema stabilizacije valjanja određuje način stvaranja normalne aerodinamičke sile i tip SULR, a karakter određuje način pretvaranja signala vođenja u otklone organa upravljanja. Poremećajni aerodinamički momenat valjanja nastaje pri nesimetričnom opstrujavanju rakete, najvećim delom preko komponente tog momenta nastalog kosim opstrujavanjem i nelinearnom zavisnošću od uglova $\alpha, \beta$, $\delta_{\mathrm{h}}, \delta_{\mathrm{v}}$, usled čega se unakrsne veze i javljaju. Da bi se obezbedile dobre karakteristike prelaznog procesa i određena veličina greške $u$ stacionarnom stanju, signal upravljanja treba da sadrži i signal proporcionalan sa ugaonom brzinom valjanja, što se obezbeđuje povratnom spregom brzinskim žiroskopom - slika 6 .

Iz opšte blok šeme stabilizacije valjanja rakete sledi:
Blok šema na slici 6 pokazuje strukturu u kojoj se povratna sprega, po uglu valjanja $\gamma$, obezbeđuje programski, numeričkom integracijom ugaone brzine valjanja $\omega_{\mathrm{x}}$, sa brzinskog žiroskopa. Zadata vrednost ugla valjanja $\gamma_{z}$ (u opštem slučaju $\gamma_{z} \neq 0$ ) obezbeđuje se takođe programski, memorisanjem ugla valjanja u momentu lansiranja rakete, odnosno ,zabravljivanjem" GSN rakete na cilj (komandom sa nosača - broda).

Funkcija prenosa rakete u blok šemi sa slike 6 (po brzini valjanja u odnosu na otklon elerona) data je jednačinom:

$$
\begin{aligned}
& \frac{\omega_{x}(s)}{\delta_{e}(s)}=\frac{K_{\omega_{x}}}{T_{\omega_{x}} s+1} ; \\
& T_{\omega_{x}}=-\frac{1}{K_{\omega_{x}} C_{l}^{\omega_{x}}},
\end{aligned}
$$

a na isti način definišu se i funkcije prenosa uzdužnog kretanja rakete

$$
\left(\frac{\omega_{z}(s)}{\delta_{v}(s)}, \frac{n_{y}(s)}{\delta_{v}(s)}\right. \text { itd.). }
$$

Funkcije prenosa rakete najpreglednije pokazuju odnose kao što su otkloni komandnih površina sa kinematskim veličinama (uglovi, uglovne brzine i normalna ubrzanja), a računaju se iz linearizovanih i redukovanih modela sistema.

$$
\begin{aligned}
& \frac{\gamma}{\gamma_{z}}=\frac{-K_{s} K_{e}}{\left(\frac{s^{2}}{\omega_{n s}^{2}}+\frac{2 \mu_{s}}{\omega_{n s}} s+1\right) s\left(T_{e} s+1\right)+\left(-K_{s}\right) K_{e} K_{d g} G_{k}(s)} \\
& \frac{\omega_{x}}{\gamma_{z}}=\frac{s G_{\gamma}(s)\left(-K_{s} K_{e}\right)}{\left(\frac{s^{2}}{\omega_{n s}^{2}}+\frac{2 \mu_{s}}{\omega_{n s}} s+1\right) s\left(T_{e} s+1\right)+s\left[-K_{s} K_{e} K_{d g} G_{k}(s)\right]+G_{\gamma}(s)\left(-K_{s} K_{e}\right)}
\end{aligned}
$$




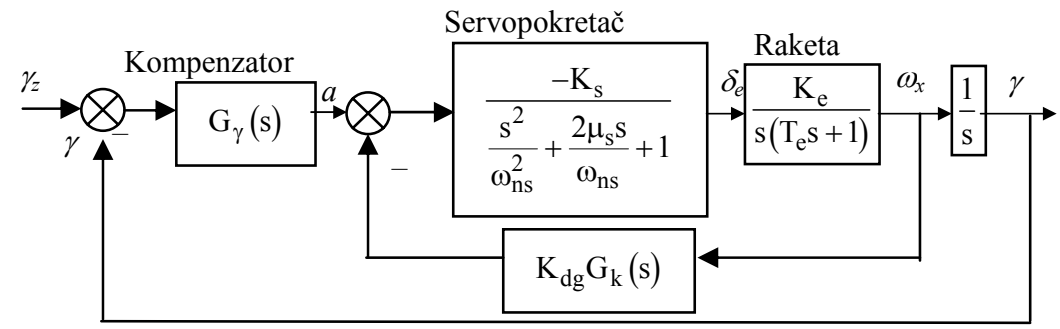

Sl. 6-Opšta blok šema stabilizacije valjanja rakete

\section{Model cilja}

U ovom simulacionom modelu smatra se da raketa u zadatom trenutku zahvata cilj i da je u trenutku lansiranja moguće dobiti početne podatke o brzini i daljini cilja, dok se za početno ubrzanje cilja uzima nula. $U$ radu nije obrađen model scene, budući da se ne razmatra uticaj određenih odnosa na detekciju cilja (udaljenost, oblik i veličina cilja, energetski kontrast, lažni ciljevi itd.). Matematički model kretanja cilja može se predstaviti diferencijalnim jednačinama kretanja centra mase cilja u geodetskom KS. Za poznata ubrzanja cilja u geodetskom KS matematički model kretanja cilja opisuje se sa šest diferencijalnih jednačina, iz kojih se integracijom dobijaju linearne komponente brzine i koordinate položaja centra mase cilja u geodetskom KS. Diferencijalne jednačine kretanja cilja u geodetskom KS su:

$\left|\begin{array}{l}\dot{V}_{c x g} \\ \dot{V}_{c y g} \\ \dot{V}_{c z g}\end{array}\right|=\left|\begin{array}{l}a_{c x g} \\ a_{c y g} \\ a_{c z g}\end{array}\right|$

$\left|\begin{array}{l}\dot{x}_{c g} \\ \dot{y}_{c g} \\ \dot{z}_{c g}\end{array}\right|=\left|\begin{array}{l}V_{c x g} \\ V_{c y g} \\ V_{c z g}\end{array}\right|$
Komponente ubrzanja cilja u geodetskom KS u jednačini (35) mogu se dobiti projektovanjem apsolutne brzine cilja $\vec{V}_{c}$, u odgovarajućem kinematskom sistemu cilja, na ose geodetskog KS. U matričnoj formi taj vektor je:

$$
\overrightarrow{\mathrm{V}}_{\mathrm{cg}}=\mathrm{L}_{\Psi_{\mathrm{c}}}^{\mathrm{T}} \mathrm{L}_{\Theta_{\mathrm{c}}}^{\mathrm{T}}\left|\begin{array}{l}
\mathrm{V}_{\mathrm{c}} \\
0 \\
0
\end{array}\right|
$$

gde su $\mathrm{L}_{\Psi_{c}}^{\mathrm{T}}$ i $\mathrm{L}_{\Theta_{\mathrm{c}}}^{\mathrm{T}}$ matrice transformacije iz kinematskih KS cilja u geodetski KS. ima oblik:

U skalarnoj formi jednačina (37)

$V_{c x g}=V_{c} \cos \Theta_{c} \cos \Psi_{c}$

$V_{c y g}=V_{c} \sin \Theta_{c}$

$V_{c z g}=-V_{c} \cos \Theta_{c} \sin \Psi_{c}$

Projektovanjem apsolutnog ubrzanja cilja $\vec{a}_{c} u$ odgovarajućim kinematskim sistemima na ose geodetskog KS, u matričnoj formi biće:

$\vec{a}_{c g}=L_{\Psi_{c}}^{T} L_{\Theta_{c}}^{T}\left[a_{c x}, a_{c y}, a_{c z}\right]^{T}$ 
odnosno u skalarnoj formi:

$$
\begin{aligned}
& a_{c x g}=\dot{V}_{c} \\
& a_{c y g}=V_{c} \dot{\Theta}_{c} \\
& a_{c z g}=-V_{c} \Psi_{c} \cos \Theta_{c}
\end{aligned}
$$

$\mathrm{Na}$ osnovu prethodnih jednačina, skalarni izrazi za komponente ubrzanja cilja u geodetskom KS biće:

$$
\begin{aligned}
& a_{c x g}=\dot{V}_{c} \cos \Theta_{c} \cos \Psi_{c}-V_{c} \dot{\Theta}_{c} \sin \Theta_{c} \\
& \cos \Psi_{c}-V_{c} \frac{d \Psi}{d t_{c}} \cos \Theta_{c} \sin \Psi_{c} \\
& a_{c y g}=\dot{V}_{c} \sin \Theta_{c}+V_{c} \dot{\Theta}_{c} \cos \Theta_{c} \\
& a_{c z g}=-\dot{V}_{c} \cos \Theta_{c} \sin \Psi_{c}+V_{c} \dot{\Theta}_{c} \sin \Theta_{c} \sin \Psi_{c}- \\
& -V_{c} \frac{d \Psi}{d t_{c}} \cos \Theta_{c} \cos \Psi_{c}
\end{aligned}
$$

Modul brzine cilja $V_{c}$, ugao nagiba trajektorije cilja $\Theta_{c}$ i ugao zakreta trajektorije cilja $\Psi_{c}$ određuju se integracijom tri dodatne diferencijalne jednačine, koje se dobijaju iz jednačina opterećenja cilja u kinematskom KS vezanom za cilj:

$$
\begin{aligned}
& n_{c x}=\frac{\dot{V}_{c}}{g} ; \quad n_{c y}=\frac{V_{c} \dot{\Theta}_{c}}{g} ; \\
& n_{c z}=\frac{-V_{c} \frac{d \Psi}{d t_{c}}}{g} \cos \Theta_{c}
\end{aligned}
$$

pa je sada:

$$
\dot{V}_{c}=n_{c x} g ; \dot{\Theta}_{c}=n_{c y} \frac{g}{V_{c}} ; \frac{d \psi}{d t}=\frac{-n_{c z} g}{V_{c} \cos \Theta_{c}}
$$

Vektor opterećenja cilja u kinematskom KS je pri tome bio:

$$
n_{c}=\left[\begin{array}{lll}
n_{c x} & n_{c y} & n_{c z}
\end{array}\right]^{T}
$$

i zadaje se kao deterministička ili slučajna funkcija vremena sa poznatim statičkim karakteristikama slučajnog procesa.

\section{Zaključak}

U radu je formiran matematički model za simulaciju leta konkretne protivbrodske rakete. Ovaj model je verifikovan i kroz softver za simulaciju [7], čime je otvorena mogućnost sinteze novog autopilota sa brzinskim žiroskopima kao senzorima, koji bi omogućio osavremenjavanje. Programi za simulaciju sistema za upravljanje letom protivbrodske rakete dati su u [7]. Model omogućava detaljnu analizu procesa vođenja, za čime se ukazala potreba za vreme eksploatacije rakete. Zbog toga je, pored opisa objekta, data i mogućnost analize uticaja slučajnih grešaka, kao što su greške u zauzimanju početnih parametara, greške merenja (naročito glave za samonavođenje), kao i ostalih šumova u električnom sistemu autopilota (žiroskopi, sabirači itd.).

Model omogućava simulaciju rakete u realnim uslovima, uključujući uticaj vetra i veštačkih smetnji. Suština simulacije je u identifikaciji parametara radi verifikacije rezultata ponašanja rakete prilikom gađanja (u prvom i završnom delu putanje). Analizirani simulacioni model sistema za upravljanje letom protivbrodske rakete nalazi se u praktičnoj upotrebi i daje osnovu za dalja proučavanja ove klase ra- 
keta. Koncipiran je tako da se svaki od modula sistema može zameniti modelom željene kompleksnosti, odnosno tačnosti, kako podsistema, tako i sistema u celini. Model omogućava dalji rad u cilju simulacije u realnom vremenu ili sa neposrednom primenom HIL (Hardware In the Loop) simulacija, zamenom posmatranog modula realnim podsistemom. Ideja je da se simulirani model proširuje i koristi $u$ edukativne svrhe.
Literatura:

[1] Korn, G. A.: Modeliranje slučajnih procesa u analognim uređajima, Mir, Moskva, 1985.

[2] Pucelev, A. V.: Statistička analiza i sinteza složenih dinamičkih sistema, Mašinostroenie, Moskva, 1984.

[3] Krutko, P. D. i dr.: Algoritmi i programi projektovanja automatskih sistema, Radio i veze, Moskva, 1988.

[4] Fitzgerald, R. J.: Reduction Of Missile Navigation Errors by Roll Programing, J. Guidance, VOL. 13, No. 4, 1990.

[5] Đekić, M.: Prilog razvoju novih algoritama vođenja kod samonavođenih raketa, magistarski rad, Beograd, 1993.

[6] Nelson, C. R.: Flight Stability and Automatic Control, McGraw-Hill, New York, 1989.

[7] Gaćeša, N.: Sistem za upravljanje letom protivbrodske rakete sa radarskom glavom za samonavođenje, magistarski rad, Beograd, 2003. 